CLINICAL STUDY

\title{
Weight loss in prepubertal obese children is associated with a decrease in adipocyte fatty-acid-binding protein without changes in lipocalin-2: a 2-year longitudinal study
}

\author{
Raquel Corripio $^{1}$, José-Miguel Gónzalez-Clemente ${ }^{2}$, Jacobo Pérez-Sánchez ${ }^{1}$, Sílvia Näf ${ }^{3}$, Lluís Gallart ${ }^{3,4}$, \\ Ramon Nosàs ${ }^{1}$, Joan Vendrell ${ }^{3}$ and Assumpta Caixàs ${ }^{2}$ \\ Departments of ${ }^{1}$ Pediatric Endocrine and ${ }^{2}$ Diabetes, Endocrinology and Nutrition, Hospital de Sabadell, Institut Universitari Parc Taulí, Universitat \\ Autònoma de Barcelona (UAB), C/Parc Taulí SN, 08208 Sabadell, Spain, ${ }^{3}$ Endocrinology and Diabetes Unit, Research Department, Hospital Universitari \\ Joan XXIII de Tarragona, Institut Pere Virgili, 43005 Tarragona, Spain and ${ }^{4}$ Centro de Investigación Biomédica en Red de Diabetes y Enfermedades \\ Metabólicas Asociadas (CIBERDEM), 43005 Tarragona, Spain
}

(Correspondence should be addressed to A Caixàs; Email: acaixas@tauli.cat)

\begin{abstract}
Context: Lipocalin-2 and adipocyte fatty-acid-binding protein (A-FABP or FABP4) are adipokines potentially involved in the pathophysiology of obesity and metabolic syndrome in adults. In children, they have been scarcely studied.

Objective: To analyze lipocalin-2 and A-FABP circulating levels before and after 2 years of a dieting and lifestyle intervention in a prepubertal obese cohort.

Design and setting: Case-control study with a prospective follow-up of cases for 2 years in our referral pediatric endocrine outpatient center.

Patients and methods: Seventy-three prepubertal obese children, 8.03 \pm 1.08 -years old, and 47 age- and gender-matched lean controls were studied. Anthropometric parameters, blood pressure, fasting oral glucose tolerance test, homeostatic model insulin resistance index (HOMA-IR), lipid profile, lipocalin-2, and A-FABP were evaluated. Weight loss was considered if $z$-score body mass index (BMI) decreased at least 0.5 S.D.

Results: At baseline, lipocalin-2 and A-FABP were higher in prepubertal obese children than those in lean controls $(P<0.001)$. A-FABP showed a gradual increase, according to the obesity degree $\left(r^{2}=0.632 ; P<0.001\right)$. After 2 years, obese patients who lost weight showed a decrease in A-FABP (a mean $2 \%$ reduction in BMI was associated with a mean $29 \%$ decrease in A-FABP $(P<0.001)$ ) without changes in lipocalin-2 levels. Regression model analysis adjusted by age, sex, BMI, and HOMA showed that A-FABP was lower in males $(\beta=-5.77$ (CI 95\%: $-9.7 ;-1.84)$ ) and was modified by BMI $\left(\beta=2.7\right.$ (CI 95\%: 1.77-3.62), $\left.r^{2}=0.659\right)$. Lipocalin-2 was not modified by any of these variables. Conclusions: Prepubertal obese children show high plasma lipocalin-2 and A-FABP levels, but only A-FABP is influenced by weight loss.
\end{abstract}

European Journal of Endocrinology 163 887-893

\section{Introduction}

Obesity is the sixth most important risk factor contributing to the overall burden of disease worldwide (1) and is associated with a constellation of metabolic derangements during the pediatric age (2). Childhood obesity can be tracked into adulthood (3) and has significant adverse health consequences (4).

Adipose tissue is not only an energy store but also an authentic endocrine organ, which carries out its functions through adipokines (5). Over the past years, efforts have been made to identify new markers for cardiometabolic risk, which are lipocalin-2 and adipocyte fatty-acid-binding protein (A-FABP or FABP4) (6-10). Lipocalin-2, also known as 24p3 (LCN2) or siderocalin or neutrophil gelatinase-associated lipocalin, is a $25 \mathrm{kDa}$ protein, which was originally identified in mice kidney cells and in human granulocytes. The physiological functions of this protein remain less understood. Previous studies have focused on its role in immune response to bacterial infections (11). Recently, it has been studied as a biomarker for acute kidney failure (12). The relationship between lipocalin2 and obesity is controversial. Lipocalin- 2 has not previously been studied in children.

A-FABP belongs to FABPs family. They are $14-15 \mathrm{kDa}$ cytosolic proteins, which bind to hydrophobic ligands such as fatty acids, eicosanoids, and other lipids and they are involved in lipid metabolism (13). In humans, adipocytes and differentiated macrophages express A-FABP (14). A-FABP was studied in a small heterogeneous group of obese children at different pubertal 
stages. They reported high plasma levels that decreased after 1-year weight loss (15). A-FABP gene variants were also studied in a cohort of prepubertal children and the authors found that selective SNPs may account for increased risk for insulin resistance or systemic inflammation in the context of obesity (16).

To our knowledge, no previous 2-year prospective studies regarding the role of lipocalin-2 and A-FABP in prepubertal obese children has been carried out.

The aim of this study is to gain some insight into the effect of weight loss after a 2-year diet and lifestyle intervention program on lipocalin-2 and A-FABP circulating levels in a prepubertal obese cohort. This effect was evaluated taking into account the obesity degree, the metabolic syndrome components, and the insulin resistance.

\section{Patients and methods}

We examined 73 obese prepubertal children aged 6-10 years who were attending an outpatient long-term intervention program over a period of 2 years. Inclusion criteria were the existence of obesity as defined by body mass index (BMI) $>2$ SDS for age and sex upon Spanish normative charts (17), aged between 6 and 10 years and prepubertal according to Tanner staging $(18,19)$. Controls were healthy, lean children attending preoperative blood analysis before minor surgery, prepubertal and matched by age with the obese patients. Exclusion criteria were the presence of endocrinopathy, obesity-associated syndrome, the presence of any infectious or inflammatory diseases in the past 10 days, or taking medication that affected weight, lipidic metabolism, or arterial pressure. Written informed consent was obtained from all the patients parents and all investigations followed the Helsinki Declaration. The study was approved by the ethical committee of our institution (reference code 2004104).

\section{Baseline clinical evaluation}

Detailed medical, personal, and family history of obesity and cardiometabolic risk were obtained from all subjects, including birth weight and length for gestational age. A complete physical examination was performed with special attention to the existence of acanthosis nigricans. Height was measured using a Harpenden stadiometer to the nearest $0.1 \mathrm{~cm}$, body weight was measured with a balance scale to the nearest $0.1 \mathrm{~kg}$, and waist circumference was measured with a tape at the middle point between the last rib and the superior iliac crest, adjusted to the nearest $0.1 \mathrm{~cm}$ and compared with an age- and sex-reference population (20). All these measurements were performed for duplication and by the same investigator, with patient in light clothes and without shoes. The mean of two determinations was used for calculations. Adiposity was evaluated by BMI (calculated as the weight in kilograms divided by the square of the height in meters) and BMI SDS. Pubertal development was assessed by direct physical examination according to Tanner staging ( $\mathrm{I}=$ prepubertal). Blood pressure $(\mathrm{BP})$ was measured in triplicate with the Critikon Dinamap 8100 automatic system, with an appropriate sized cuff and after at least $10 \mathrm{~min}$ resting in supine position. Lowest $\mathrm{BP}$ was chosen and was evaluated using the percentiles of International Task Force for BP (21).

Obesity degree was fixed with $z$-score using the LMS method (22). To explore the impact of the definition of obesity on the frequency of cardiometabolic features, we also applied the obesity criteria by Cole (International Obesity Task Force) (23) to our BMI data.

\section{Baseline metabolic evaluation}

We obtained a blood sample after a $12 \mathrm{~h}$ overnight fast. A lipid profile, alaninetransferase (ALT), uric acid, glucose, and insulin levels were determined. Likewise, a standard $2 \mathrm{~h}$ oral glucose tolerance test was performed in obese subjects.

Samples were stored at $-80{ }^{\circ} \mathrm{C}$ until their analysis. Plasma glucose was measured by the glucose hexokinase method, insulin by an electrochemiluminescent method, cholesterol and its fractions by cholesterol sterase/oxidase, and triglycerides by lypase/glycerol kinase (Roche Diagnostics). Intra- and interassay coefficient of variation $(\mathrm{CV})$ values were $1.9-2.1 \%$ for glucose and $2.6-2.8 \%$ for insulin respectively.

Plasma lipocalin-2 was measured by the ELISA Human Lipocalin-2/NGAL ELISA (BioVendor R\&D, Modrice, Czech Republic) having a sensitivity of $0.02 \mathrm{ng} / \mathrm{ml}$ with intra- and inter-assay CV values $<10$ and $<9 \%$ respectively. Plasma A-FABP and human adipocyte FABP4 were measured by the ELISA (BioVendor R\&D) having a sensitivity of $0.1 \mathrm{ng} / \mathrm{ml}$ with intraand interassay $\mathrm{CV}$ values $<6$ and $<7 \%$ respectively.

Impaired glucose metabolism was defined according to the American Diabetes Association (ADA) criteria (24). Insulin resistance was evaluated using the homeostatic model index (HOMA-IR = fasting insulin $(\mu \mathrm{U} / \mathrm{ml}) \times$ fasting glucose $(\mathrm{mmol} / \mathrm{l}) / 22.5)(25)$.

\section{Intervention and follow-up}

After the baseline evaluation, balanced normocalorie diet adjusted by age (orally and written) and a personally adapted exercise program was given to obese patients. The diet contained $30 \%$ of energy as fat, $15 \%$ of energy as proteins, and $55 \%$ of energy as carbohydrates ( $5 \%$ as sugar). The children and their parents followed a 'traffic-light system' when selecting their food. Television viewing and video games were limited to a maximum of $2 \mathrm{~h} /$ day, and 30-45 min of moderate exercise three times a week was negotiated. Visits were programed every 4 months for 2 years. 
Table 1 Baseline subject characteristics. Data are presented as mean \pm s.D. or percentages.

\begin{tabular}{|c|c|c|c|}
\hline & Obese & Control & $P$ \\
\hline$n$ & 73 & 47 & \\
\hline Sex & 36 boys $/ 37$ girls & 31 boys $/ 16$ girls & 0.073 \\
\hline Age (years) & $8.03 \pm 1.08$ & $7.74 \pm 1.35$ & 0.22 \\
\hline $\mathrm{BMI}\left(\mathrm{kg} / \mathrm{m}^{2}\right)$ & $26.5 \pm 3.07$ & $16.2 \pm 1.41$ & $<0.001$ \\
\hline$z$-BMI (S.D.) & $4.76 \pm 1.67$ & $-0.27 \pm 0.74$ & $<0.001$ \\
\hline Birth weight (g) & $3337 \pm 599.5$ & $3194 \pm 539.9$ & 0.28 \\
\hline Birth length $(\mathrm{cm})$ & $50.0 \pm 2.61$ & $50.1 \pm 1.60$ & 0.3 \\
\hline Familiar diabetes 2 & $35(47 \%)$ & $11(23 \%)$ & 0.01 \\
\hline Father BMI $\left(\mathrm{kg} / \mathrm{m}^{2}\right)$ & $28.6 \pm 3.93$ & $25.2 \pm 2.31$ & 0.003 \\
\hline Mother BMI $\left(\mathrm{kg} / \mathrm{m}^{2}\right)$ & $29.1 \pm 7.83$ & $23.1 \pm 3.22$ & 0.001 \\
\hline Acanthosis & $23(31 \%)$ & $0(0 \%)$ & $<0.001$ \\
\hline Waist $(\mathrm{cm})$ & $81.3 \pm 8.5$ & $57.5 \pm 6.05$ & 0.035 \\
\hline $\mathrm{SBP}(\mathrm{mmHg})$ & $109.2+14.5$ & $104.1+9.60$ & 0.026 \\
\hline $\mathrm{DBP}(\mathrm{mmHg})$ & $63.4 \pm 8.32$ & $64.1 \pm 9.25$ & 0.672 \\
\hline Glucose $(\mathrm{mg} / \mathrm{dl})$ & $83.7+7.78$ & $83.3+5.04$ & 0.804 \\
\hline Insulin $(\mu \mathrm{U} / \mathrm{ml})^{\mathrm{a}}$ & $10(5-15)$ & $4(2-5)$ & $<0.001$ \\
\hline HOMA-IR ${ }^{a}$ & $1.97(1.02-3.14)$ & $0.80(0.40-1.08)$ & $<0.001$ \\
\hline Cholesterol (mg/dl) & $155.5 \pm 27.9$ & $157.8 \pm 31.4$ & 0.621 \\
\hline Triglycerides $(\mathrm{mg} / \mathrm{dl})^{a}$ & $69(52.5-87.5)$ & $48(40-54)$ & $<0.001$ \\
\hline $\operatorname{LDLc}(\mathrm{mg} / \mathrm{dl})$ & $93.5 \pm 24.1$ & $82.6 \pm 24.7$ & 0.032 \\
\hline $\mathrm{HDLC}(\mathrm{mg} / \mathrm{dl})$ & $51.3 \pm 12.8$ & $65.5 \pm 14.7$ & $<0.001$ \\
\hline Uric acid (mg/dl) & $4.12+0.85$ & $3.41+0.626$ & $<0.001$ \\
\hline ALT (U/I) & $20.1 \pm 6.68$ & $19.2 \pm 6.97$ & 0.479 \\
\hline A-FABP $(n g / m l)$ & $35.2+14.6$ & $10.4+4.54$ & $<0.001$ \\
\hline Lipocalin-2 (ng/ml) & $50.7 \pm 18.4$ & $28.0 \pm 7.75$ & $<0.001$ \\
\hline
\end{tabular}

A-FABP, adipocyte fatty-acid-binding protein; ALT, alaninetransferase; BMI, body mass index; DBP, diastolic blood pressure; HDLc, high-density lipoprotein cholesterol; HOMA-IR, homeostatic model insulin resistance index; LDLc, low-density lipoprotein cholesterol; SBP, systolic blood pressure. ${ }^{\mathrm{a}}$ Median (interquartile range).

\section{Re-evaluation}

After 2 years, the same clinical and metabolic evaluation was performed in the obese patients. We considered a significant weight loss if $z$-BMI had decreased at least 0.5 S.D. (26).

\section{Statistical analysis}

Data were expressed as mean \pm s.D. for quantitative variables and as percentages for categorical variables unless otherwise indicated. Logarithmical transformation before the analysis was used when variables were not normally distributed. Two-year percentage of change was calculated as (end value-initial value)/ initial value $\times 100$. $t$-Test or Mann-Whitney $U$ test was used for comparing differences between the groups, and paired $t$-test or Wilcoxon test was used to compare variables before and after the intervention. Bivariated correlations were evaluated with Pearson's and Spearman's coefficients as appropriate. Furthermore, we used some multivariate linear regression models using either lipocalin-2 or A-FABP as a dependent variable and including age, sex, weight status (BMI), and HOMA as independent variables. A $P$ value $<0.05$ was considered as significant. All analyses were performed with SPSS 17.0 version (SPSS, Chicago, IL, USA).

\section{Results}

Seventy-three obese children (50.6\% girls) and 47 healthy controls ( $34 \%$ girls) were included in the study. The subject characteristics are shown in Table 1. Obese children had more acanthosis, insulin resistance, high $\mathrm{BP}$, insulin, triglycerides, low-density lipoprotein cholesterol (LDLc), urate, ALT, and lower high-density lipoprotein cholesterol (HDLc) levels than controls. Lipocalin-2 and A-FABP levels were increased in obese children as compared with lean controls (Table 1).

According to Cole charts, $4 \%(n=3)$ of our patients should be classified as overweight and not obese. We did not find significant differences in these two subgroups with respect to any analyzed variable.

In obese children, A-FABP showed a positive correlation with BMI $(r=0.499 ; P<0.001)$, waist perimeter $(r=0.406 ; \quad P<0.001)$, diastolic BP $(r=0.244$; $P=0.043)$, triglycerides $(r=0.310 ; P=0.008)$, uric acid $\quad(r=0.264 ; \quad P=0.025), \quad$ ALT $\quad(r=0.252$; $P=0.033)$, and HOMA-IR $(r=0.255 ; P=0.033)$ and a negative one with HDLc $(r=-0.268 ; P=0.023)$.
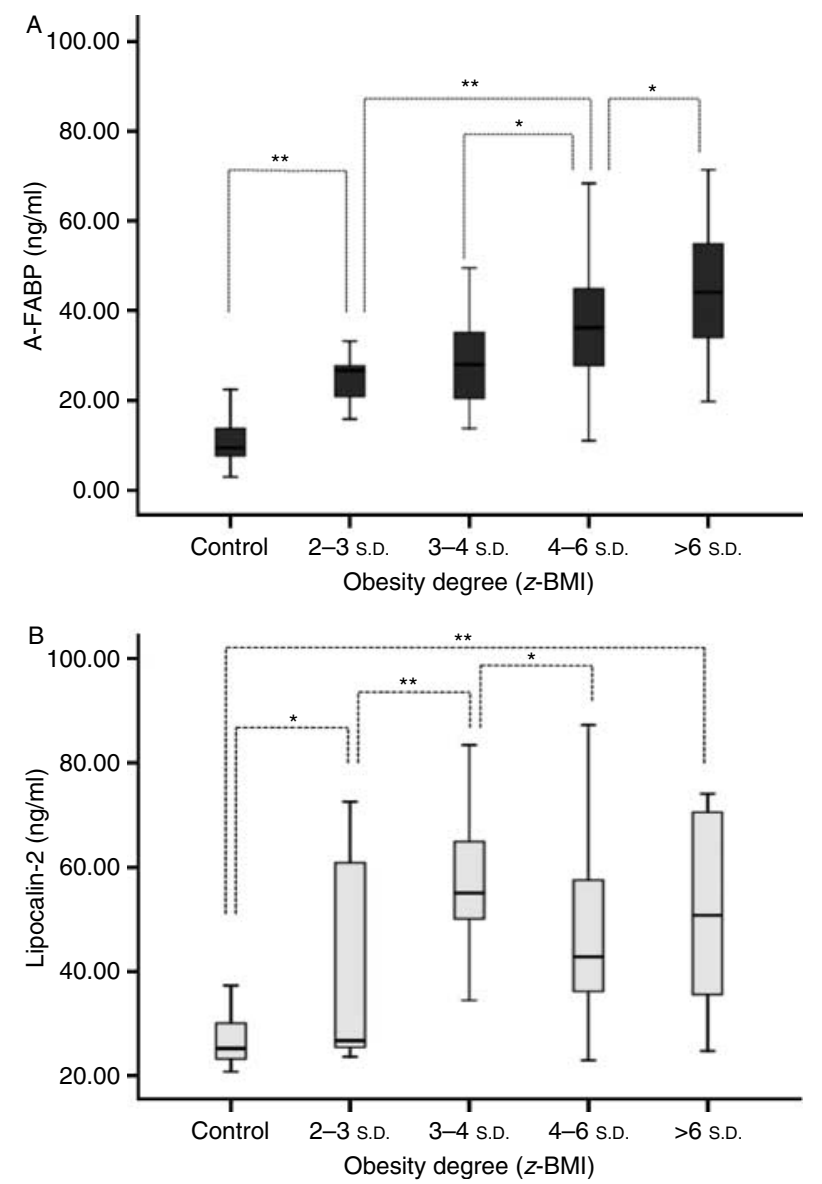

Figure 1 Box-plot showing plasma A-FABP (A) and lipocalin-2 (B) concentrations according to the degree of obesity. $z$-BMI, $z$-score body mass index. ANOVA test was used. ${ }^{\star} P<0.05 ;{ }^{\star \star} P<0.001$. 
Neither did lipocalin-2 correlate with any anthropometrical and metabolic studies nor did it vary with A-FABP.

ANOVA showed that A-FABP levels rose gradually while increasing the obesity degree $(F=40.6 ; P<0.001)$ (Fig. 1A). Lipocalin-2 levels were clearly higher in obese than in healthy lean controls, but this increase was not lineal according to the obesity degree (Fig. 1B).

After a 2-year follow-up, 62 patients completed the study and 11 (drop outs $=15 \%$ ) did not. We classified the obese patients who finished the study according to the presence of weight loss: 31 with a significant weight loss and 31 without it (Table 2). Baseline comparison between these two groups was not significant except for age and waist circumference. The obese patients who lost weight were older and had a higher waist circumference than those who did not lose weight. It is noteworthy that both the groups had similar baseline circulating levels of A-FABP and lipocalin-2.

After 2 years, a substantial weight loss led to a significant decrease in A-FABP (Fig. 2A). A weight loss of $2 \%$ in BMI was associated with a reduction in $z$-BMI of $27 \%$, in $z$-waist of $15.6 \%$, and in A-FABP of $29 \%$. In addition, the correlation of $z$-BMI (in percentage of change) with A-FABP (in percentage of change) was $0.579(P<0.001)$. Lipocalin-2 remained unchanged after the 2-year intervention program (Fig. 2B).

To further understand the relationship between A-FABP and lipocalin-2 and the rest of the variables evaluated, we carried out different multivariate linear regression analysis with each of them. Lipocalin-2 and A-FABP were considered as dependent variables, and healthy control group, age, sex, weight status (BMI), and HOMA were included as independent variables. In addition, we analyzed the influence of any significant variable in the previous bivariate correlations. In the model, A-FABP levels were modified by sex (male $\beta=-5.77$ (IC 95\%: -9.7 to 1.84 )) and BMI ( $\beta=2.7$ (CI 95\%: 1.77-3.62, $r^{2}$ for the model 0.659)). However, age, HOMA, and belonging to the control group did not influence A-FABP levels. In obese patients, correlations of A-FABP with the components of metabolic syndrome were lost after adjusting for BMI. Lipocalin-2 did not differ between genders and was higher in obese patients (obese $\beta=21.91$ (CI 95\%: 8.93-34.9, $r^{2}$ for the model $=0.377)$ ).

A-FABP levels after 2 years of follow-up, which depended on baseline A-FABP $(\beta=0.48$ (CI 95\%: 0.25-0.7)), were higher in those patients without weight loss $(\beta=6.81$ (IC 95\%: 0.096-13.5)) and were modified by BMI ( $\beta=0.91$ (CI 95\%: -0.08 to 1.91 ). Lipocalin-2 was not modified by any of these variables.

\section{Discussion}

To our knowledge, this is the first 2-year longitudinal study that evaluates the association between plasma adipokine concentrations (lipocalin-2 and A-FABP)

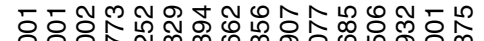
०.00000000000000

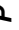

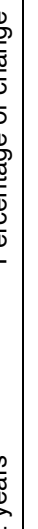

0
$\frac{1}{3}$
0
0
0
0
0

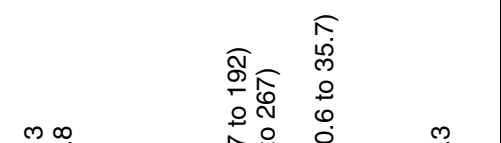

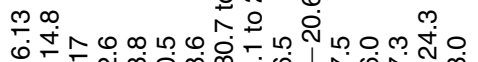
$+1+10 \sim$

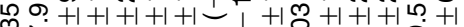
Nลิ

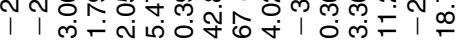
然 $\stackrel{\frac{9}{\partial}}{\circ}$

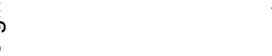
ए人o $+\infty+\infty \div \infty \infty+\infty$

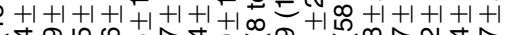

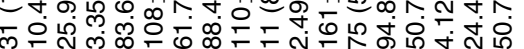

离

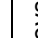

Non 0 L $-1+1+1+1+1+1+100+1 \leq+1+1+1+1+1$

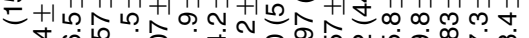

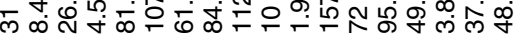

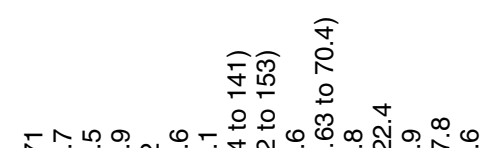

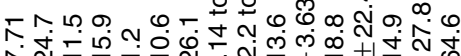

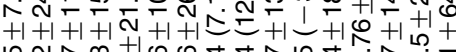

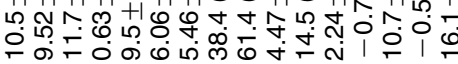

$\frac{\widehat{D}}{\frac{\bar{\sigma}}{0}}$<smiles>CCOCCOCCO</smiles>

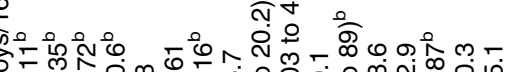

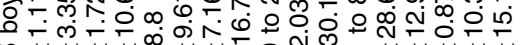

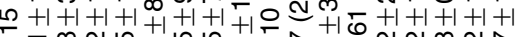

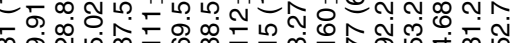
(2)

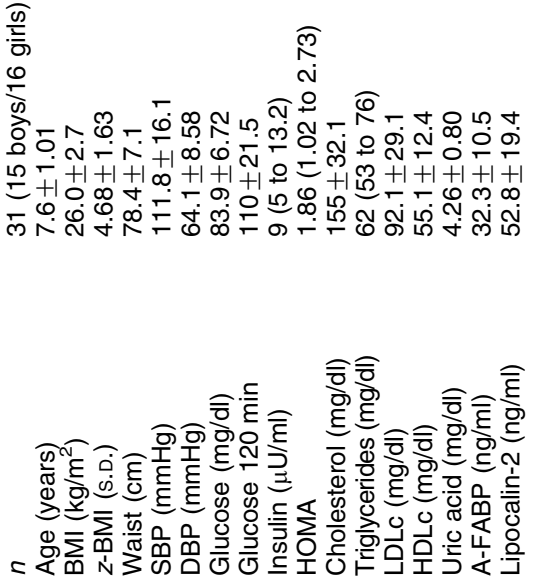



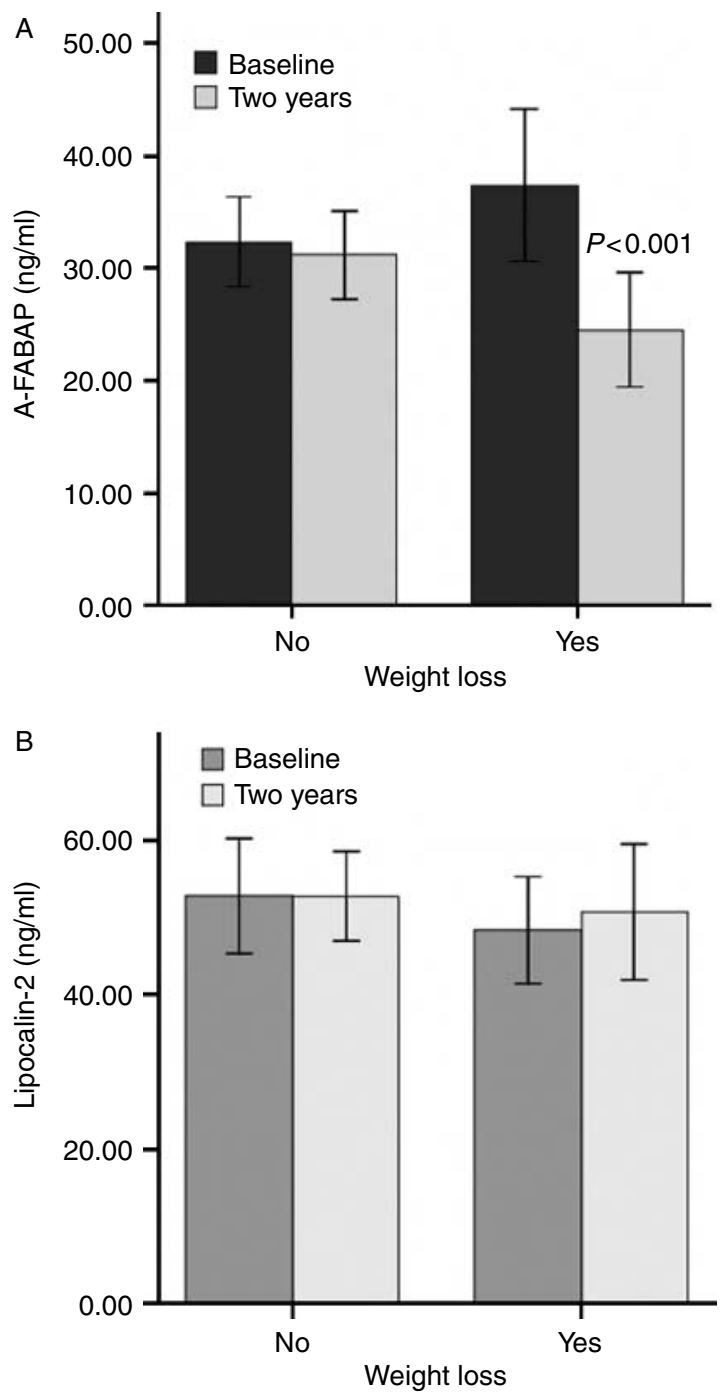

Figure 2 A-FABP (A) and lipocalin-2 (B) at baseline and after a 2 -year intervention according to weight loss. Weight loss had occurred if baseline $z$-BMI minus 2-year $z$-BMI $\geq 0.5$ s.D. $z$-BMI, $z$-score body mass index. Data are expressed as means \pm s.D. Paired $t$-test was used.

and metabolic syndrome parameters in a prepubertal children group, before and after a diet and lifestyle intervention program. We hypothesized that in prepubertal obese children, plasmatic lipocalin-2 and A-FABP would be increased compared with lean children and would decrease after a significant weight loss.

Lipocalin-2 in our obese prepubertal children showed a $44.7 \%$ higher concentration than that in lean children, after controlling for age and sex. A previous study in adults showed higher concentrations of plasmatic lipocalin-2 in obese subjects (10), but these results have not been corroborated by other authors (27). It is noteworthy that, despite obtaining clear differences between obese and lean children in our studied cohorts, lipocalin-2 levels were not related to BMI and waist circumference. This is in contrast to a unique cross-sectional study in adolescents (28), which was carried out with 80 obese girls, with different pubertal stages, and mixed groups for calculating correlations that could have misled the results.

Likewise, in our study, lipocalin-2 concentrations did not significantly decrease after weight loss in obese patients after 2 years of follow-up. We know that there is no clear explanation for this observation. However, sources other than adipose tissue such as liver, lung, and macrophages could contribute to the circulating concentrations of this protein $(29,30)$, and therefore justify our observations.

Lipocalin-2 appears to act as an acute phase protein, which can be induced by different inflammatory processes (31). In obesity, it has been shown to be an independent predictor of inflammation and it correlates with PCR after adjusting for age, sex, and adiposity (10). In this sense, one is tempted to speculate that the presence of higher plasma lipocalin-2 concentrations in obese children may represent an epiphenomenon of a low-grade systemic inflammation. Consequently, lipocalin-2 could represent a possible link between obesity and cardiovascular risk. In contrast, some studies in mice suggest that lipocalin-2 could be a protector mechanism against inflammation over activation through the suppression of lipopolysaccharide-induced cytokine production (32). Therefore, the real physiological role of lipocalin-2 is unknown to date. Whether it is an inflammatory marker related to obesity or just an acute phase protein in response to the inflammation associated with obesity remains unclear.

A-FABP concentrations have been related to obesity, metabolic syndrome, insulin resistance, type 2 diabetes, and cardiovascular disease in adult subjects (7-9, 33-35).

Our study showed that plasmatic concentrations of A-FABP were closely associated with obesity in prepubertal children as previously reported (16). There was a positive correlation between A-FABP levels and obesity markers (BMI and waist circumference). In addition, A-FABP levels were higher in obese than in lean children; the level increases with the degree of obesity. In fact, the more pronounced decrease in circulating A-FABP was observed only in children with a significant weight loss after the 2-year intervention study. A previous study, analyzing this adipokine in a similar cohort, has been conducted in 30 obese children aged 8-15 years (12 prepubertal), which reported a similar decrease in A-FABP plasma levels after 1-year obesity intervention in those with substantial weight loss (15). This decrease in A-FABP levels after weight loss has also been observed in massively obese subjects after bariatric surgery (36). Furthermore, a reduction in A-FABP expression in human adipose tissue after weight loss has also been 
reported (37). Taking all this information into account, it is plausible that subcutaneous adipose tissue amount and distribution appears to be one of the most important factors contributing to A-FABP circulating levels. However, taking into account that severe apnea is related to high A-FABP levels independent of obesity (38), we cannot rule out that part of A-FABP levels reduction after weight loss may be accounted for by amelioration of possible coexisting sleep apnea syndrome.

In animal experiments, some evidence suggests a role for A-FABP in insulin sensitivity regulation, lipid metabolism, and inflammation $(39,40)$. In humans, A-FABP has proved useful in predicting metabolic syndrome development in a 5-year study performed in a Chinese adult cohort, regardless of adiposity and insulin resistance (34). A positive correlation between A-FABP and high BP has previously been described in adults, as with other metabolic syndrome components. This correlation was independent of $\operatorname{BMI}(7,34)$ but could not be corroborated by others (9). Despite the strong positive correlations observed in our obese cohort between A-FABP and many cardiovascular risk factors, linear model showed that these associations disappeared after adjusting for BMI. Therefore, our study does not corroborate a relationship between A-FABP and the different components of the metabolic syndrome in prepubertal obese children, as observed in other studies with children (41) and women with polycystic ovary syndrome (42). Similarly, our results do not prove A-FABP as a marker linked to glucose homeostasis, in contrast to some previous reports in adults in which A-FABP was revealed as a useful predictive marker for type 2 diabetes development (8).

However, our results must be interpretated with caution because we did not take into account the A-FABP genetic variants. In this sense, a recent study showed that the rs1054135 allelic variant was higher and was associated with increased A-FABP levels in obese patients, while the rs16909233 variant allele was similar in obese and nonobese patients and was associated with increased HOMA values (16). Thus, it is possible that our cohort was principally composed of children with the first allelic variant, which would explain the absence of relationship between A-FABP and metabolic syndrome components.

In this study, after adjusting for BMI, boys showed lower plasma A-FABP concentrations than girls. These gender differences are similar to those found in adult studies $(8,34)$ and are attributed to the presence of more subcutaneous fat in women. However, in our study, boys' z-BMI was higher than girls' and both genders showed similar waist circumference. Therefore, we suggest that factors other than body fat may account for gender differences in prepubertal children.

In conclusion, prepubertal obese children show high plasma lipocalin-2 and A-FABP concentrations, but only A-FABP is influenced by weight loss. Further studies are required to elucidate the exact role of lipocalins in the physiopathology of obesity in prepubertal children.

\section{Declaration of interest}

The authors declare that there is no conflict of interest that could be perceived as prejudicing the impartiality of the research reported.

\section{Funding}

This project was supported by two grants from Fundació Parc Taulí (CIR2003/022 and CIR2008/0112).

\section{Acknowledgements}

We thank Mr David Suárez (Fundació Parc Taulí) and Anna Espinal (Universitat Autònoma de Barcelona) for the statistical analyses assessment.

\section{References}

1 IOTF. WHO Consultation on Obesity. Preventing and Managing the Global Epidemic Geneva: WHO, 1998.

2 Weiss R, Dziura J, Burgert T, Tamborlane W, Taksali S, Yeckel C, Allen K, Lopes M, Savoye M, Morrison J, Sherwin R \& Caprio S. Obesity and the metabolic syndrome in children and adolescents. New England Journal of Medicine 2004350 2362-2374. (doi:10. 1056/NEJMoa031049)

3 Whitaker R, Wright J, Pepe M, Seidel K \& Dietz W. Predicting obesity in young adulthood from childhood and parental obesity. New England Journal of Medicine 1997337 869-873. (doi:10. 1056/NEJM199709253371301)

4 Reilly JJ, Methven E, McDowell ZC, Hacking B, Alexander D, Stewart L \& Kelnar CJ. Health consequences of obesity. Archives of Disease in Childhood $2003 \mathbf{8 8}$ 748-752. (doi:10.1136/adc.88.9. 748)

5 Kershaw E \& Flier J. Adipose tissue as an endocrine organ. Journal of Clinical Endocrinology and Metabolism $2004892548-2556$. (doi:10.1210/jc.2004-0395)

6 van Dam R \& Hu F. Lipocalins and insulin resistance: etiological role of retinol-binding protein 4 and lipocalin-2? Clinical Chemistry 200753 5-7. (doi:10.1373/clinchem.2006.080432)

$7 \mathrm{Xu}$ A, Wang Y, Xu J, Stejskal D, Tam S, Zhang J, Wat N, Wong W \& Lam K. Adipocyte fatty acid-binding protein is a plasma biomarker closely associated with obesity and metabolic syndrome. Clinical Chemistry 200652 405-413. (doi:10.1373/clinchem.2005. 062463)

8 Tso A, Xu A, Sham P, Wat N, Wang Y, Fong C, Cheung B, Janus E \& Lam K. Serum adipocyte fatty acid binding protein as a new biomarker predicting the development of type 2 diabetes: a 10-year prospective study in a Chinese cohort. Diabetes Care 200730 2667-2672. (doi:10.2337/dc07-0413)

9 Rhee E, Lee W, Park C, Oh K, Kim B, Sung K \& Kim B. The association of serum adipocyte fatty acid-binding protein with coronary artery disease in Korean adults. European Journal of Endocrinology 2009160 165-172. (doi:10.1530/EJE-08-0665)

10 Wang Y, Lam KS, Kraegen EW, Sweeney G, Zhang J, Tso AW, Chow WS, Wat NM, Xu JY, Hoo RL \& Xu A. Lipocalin-2 is an inflammatory marker closely associated with obesity, insulin resistance, and hyperglycemia in humans. Clinical Chemistry 200753 34-41. (doi:10.1373/clinchem.2006.075614)

11 Flo T, Smith K, Sato S, Rodriguez D, Holmes M, Strong R, Akira S \& Aderem A. Lipocalin 2 mediates an innate immune response to bacterial infection by sequestrating iron. Nature $2004 \mathbf{4 3 2}$ 917-921. (doi:10.1038/nature03104) 
12 Kuwabara T, Mori K, Mukoyama M, Kasahara M, Yokoi H, Saito Y, Yoshioka T, Ogawa Y, Imamaki H, Kusakabe T, Ebihara K, Omata M, Satoh N, Sugawara A, Barasch J \& Nakao K. Urinary neutrophil gelatinase-associated lipocalin levels reflect damage to glomeruli, proximal tubules, and distal nephrons. Kidney International 200975 285-294. (doi:10.1038/ki.2008.499)

13 Coe $\mathrm{N} \&$ Bernlohr D. Physiological properties and functions of intracellular fatty acid-binding proteins. Biochimica et Biophysica Acta $19981391287-306$.

14 Fu Y, Luo N, Lopes-Virella M \& Garvey W. The adipocyte lipid binding protein (ALBP/aP2) gene facilitates foam cell formation in human THP-1 macrophages. Atherosclerosis 2002165 259-269. (doi:10.1016/S0021-9150(02)00305-2)

15 Reinehr T, Stoffel-Wagner B \& Roth C. Adipocyte fatty acid-binding protein in obese children before and after weight loss. Metabolism 200756 1735-1741. (doi:10.1016/j.metabol.2007.07.019)

16 Khalyfa A, Bhushan B, Hegazi M, Kim J, Kheirandish-Gozal L, Bhattacharjee R, Capdevila O \& Gozal D. Fatty-acid binding protein 4 gene variants and childhood obesity: potential implications for insulin sensitivity and CRP levels. Lipids in Health and Disease 201015 9-18. (doi:10.1186/1476-511X-9-18)

17 Hernández M CJ, Narvaiza JL, Rincón JM, Ruiz J, Sánchez E \& Sobradillo B. Curvas y tablas de crecimiento. Instituto sobre crecimiento y desarrollo. Fundación Orbegozo. Ed Garsi. Madrid, 1988.

18 Marshall W \& Tanner J. Variations in pattern of pubertal changes in girls. Archives of Disease in Childhood $1969 \mathbf{4 4} 291-303$. (doi:10.1136/adc.44.235.291)

19 Marshall W \& Tanner J. Variations in the pattern of pubertal changes in boys. Archives of Disease in Childhood 197045 13-23. (doi:10.1136/adc.45.239.13)

20 Serra Majem L, Ribas Barba L, Aranceta Bartrina J, Pérez Rodrigo C, Saavedra Santana P \& Peña Quintana L. Childhood and adolescent obesity in Spain. Results of the enKid study (19982000). Medicina Clínica 2003121 725-732. (doi:10.1157/ 13049799)

21 National High Blood Pressure Education Program Working Group on High Blood Pressure in Children and Adolescents. The fourth report on the diagnosis, evaluation, and treatment of high blood pressure in children and adolescents. Pediatrics 2004 114 555-576. (doi:10.1542/peds.114.2.S2.555)

22 Cole T. The LMS method for constructing normalized growth standards. European Journal of Clinical Nutrition $1990 \mathbf{4 4} 45-60$.

23 Cole TJ, Bellizzi MC, Flegal KM \& Dietz WH. Establishing a standard definition for child overweight and obesity worldwide: international survey. BMJ 2000320 1240-1243. (doi:10.1136/bmj. 320.7244.1240)

24 American Diabetes Association. Diagnosis and classification of diabetes mellitus. Diabetes Care 200427 (Supplement 1) S5-S10. (doi:10.2337/diacare.27.2007.S5)

25 Matthews D, Hosker J, Rudenski A, Naylor B, Treacher D \& Turner R. Homeostasis model assessment: insulin resistance and beta-cell function from fasting plasma glucose and insulin concentrations in man. Diabetologia 1985 28 412-419. (doi:10. 1007/BF00280883)

26 Reinehr T \& Andler W. Changes in the atherogenic risk factor profile according to degree of weight loss. Archives of Disease in Childhood 200489 419-422. (doi:10.1136/adc.2003.028803)

27 Stejskal D, Karpísek M, Humenanska V, Hanulova Z, Stejskal P. Kusnierova P \& Petzel M. Lipocalin-2: development, analytical characterization, and clinical testing of a new ELISA. Hormone and Metabolic Research 200840 381-385. (doi:10.1055/s-20081062746)

28 Kanaka-Gantenbein C, Margeli A, Pervanidou P, Sakka S, Mastorakos G, Chrousos GP \& Papassotiriou I. Retinol-binding protein 4 and lipocalin-2 in childhood and adolescent obesity: when children are not just "small adults". Clinical Chemistry 2008 54 1176-1182. (doi:10.1373/clinchem.2007.099002)
29 Liu Q \& Nilsen-Hamilton M. Identification of a new acute phase protein. Journal of Biological Chemistry $199527022565-22570$. (doi:10.1074/jbc.270.38.22565)

30 Meheus L, Fransen L, Raymackers J, Blockx H, Van Beeumen J, Van Bun S \& Van de Voorde A. Identification by microsequencing of lipopolysaccharide-induced proteins secreted by mouse macrophages. Journal of Immunology 1993151 1535-1547.

31 Lin Y, Rajala M, Berger J, Moller D, Barzilai N \& Scherer P. Hyperglycemia-induced production of acute phase reactants in adipose tissue. Journal of Biological Chemistry $2001 \mathbf{2 7 6}$ 42077-42083. (doi:10.1074/jbc.M107101200)

32 Zhang J, Wu Y, Zhang Y, Leroith D, Bernlohr DA \& Chen X. The role of lipocalin 2 in the regulation of inflammation in adipocytes and macrophages. Molecular Endocrinology 200822 1416-1426. (doi:10.1210/me.2007-0420)

33 Yeung D, Xu A, Cheung C, Wat N, Yau M, Fong C, Chau M \& Lam K. Serum adipocyte fatty acid-binding protein levels were independently associated with carotid atherosclerosis. Arteriosclerosis, Thrombosis, and Vascular Biology 200727 1796-1802. (doi:10.1161/ATVBAHA.107.146274)

$34 \mathrm{Xu} \mathrm{A}$, Tso A, Cheung B, Wang Y, Wat N, Fong C, Yeung D, Janus E, Sham P \& Lam K. Circulating adipocyte-fatty acid binding protein levels predict the development of the metabolic syndrome: a 5-year prospective study. Circulation $2007 \mathbf{1 1 5} 1537-1543$. (doi:10.1161/CIRCULATIONAHA.106.647503)

35 Stejskal D \& Karpisek M. Adipocyte fatty acid binding protein in a Caucasian population: a new marker of metabolic syndrome? European Journal of Clinical Investigation $2006 \quad 36 \quad 621-625$. (doi:10.1111/j.1365-2362.2006.01696.x)

36 Simón I, Escoté X, Vilarrasa N, Gómez J, Fernández-Real J, Megía A, Gutiérrez C, Gallart L, Masdevall C \& Vendrell J. Adipocyte fatty acid-binding protein as a determinant of insulin sensitivity in morbid-obese women. Obesity 200917 1124-1128. (doi:10.1038/oby.2008.665)

37 Fisher R, Hoffstedt J, Hotamisligil G, Thörne A \& Rydén M. Effects of obesity and weight loss on the expression of proteins involved in fatty acid metabolism in human adipose tissue. International Journal of Obesity and Related Metabolic Disorders 200226 1379-1385. (doi:10.1038/sj.ijo.0802110)

38 Lam D, Xu A, Lam K, Lam B, Lam J, Lui M \& Ip M. Serum adipocyte-fatty acid binding protein level is elevated in severe OSA and correlates with insulin resistance. European Respiratory Journal 200933 346-351. (doi:10.1183/09031936.50075408)

39 Boord J, Maeda K, Makowski L, Babaev V, Fazio S, Linton M \& Hotamisligil G. Adipocyte fatty acid-binding protein, aP2, alters late atherosclerotic lesion formation in severe hypercholesterolemia. Arteriosclerosis, Thrombosis, and Vascular Biology 200222 1686-1691. (doi:10.1161/01.ATV.0000033090.81345.E6)

40 Makowski L \& Hotamisligil G. Fatty acid binding proteins - the evolutionary crossroads of inflammatory and metabolic responses. Journal of Nutrition 20041342464 S-2468S.

41 Yun K, Kim S, Choi K \& Park H. Association between adipocyte fatty acid-binding protein levels and childhood obesity in Korean children. Metabolism 200958 798-802. (doi:10.1016/j.metabol. 2009.01.017)

42 Möhlig M, Weickert M, Ghadamgadai E, Machlitt A, Pfüller B, Arafat A, Pfeiffer A \& Schöfl C. Adipocyte fatty acid-binding protein is associated with markers of obesity, but is an unlikely link between obesity, insulin resistance, and hyperandrogenism in polycystic ovary syndrome women. European Journal of Endocrinology 2007157 195-200. (doi:10.1530/EJE-07-0102)

Received 29 August 2010

Accepted 24 September 2010 